\title{
Analysis on Tooth Profile Comparison and Contact Characteristics of Beveloid Gear
}

\author{
ZHENG Ji-Gui ${ }^{1, a^{*}}$, SONG Hong-Zhou ${ }^{1, b}$, ZHU Xiao-Rong ${ }^{1, c}$, Chen Jing ${ }^{1, d}$ and \\ DENG Ye $\mathrm{e}^{1, \mathrm{e}}$
}

\author{
${ }^{1}$ Beijing Research Institute of Precise Mechatronics and Controls, Beijing, 100076, China \\ a zhengjigui@163.com, bshz1988@foxmail.com, ${ }^{c}$ zxrtju@163.com, ${ }^{\mathrm{d}}$ chenjing@bjtu.edu.cn, e \\ michelledeng@126.com, *Corresponding author
}

Keywords: Beveloid gear; Involute; Tooth profile; Mathematical model; Contact line

\begin{abstract}
It takes distinguishing the two beveloid tooth surface as starting point and compares the differences of tooth profile from some aspects, such as forming process, sectional profile and the shape of the contact line. According to the tilting processing principles of the rack cutter and slotting cutter, the author analyzes whether the outline of the beveloid gear's transverse plane is involute, and makes definition of the involute and non-involute beveloid tooth surface; and in the same coordinate system, the author establishes mathematical model of the cutter envelope beveloid tooth surface. Though describing the relationship between the parameter, corner and displacement distance of the cutter tooth surface, the author uses the methods of vector transformation and mesh equation, and expresses the vector transformation of the beveloid tooth surface; and compares the differences of transverse plane and normal plane of gear along the normal direction, and the results of numerical calculations show that the two kinds of beveloid gears are so similar that can replace each other; what's more, the author discusses shape of the beveloid tooth surface's contact line, studies the formation principle of cutter tooth surface's point contact and the flow track, and has supplementary instruction about the differences of the two kinds of beveloid gears.
\end{abstract}

\section{Introduction}

The appearance of beveloid gear is similar to bevel gear. The tooth thickness and width of beveloid gear is changing in axial direction[1]. While there is difference between beveloid gear and bevel gear. Beveloid gear is formed by the same module cutter, and bevel gear's every spherical section has different module. Therefore bevel gear requires more stringent installation method, and anti dislocation design is needed [2].

By studying relevant literatures, it was found that beveloid gear's tooth profiles were slightly different for different processing methods[3]. The gear hobbing machining takes conjugate rack as media[4], would form a involute beveloid gear. When the parallel shaft was installed, gear pair also had the function of adjusting clearance. Domestic and foreign scholars, Mitome[5-6], Brauer[7], Wu Xutang[8-9], Zhu Caizhao, carried out further study at tooth surface's geometric parameter design and the meshing principle.

The hobbing cutter and rack cutter can only process involute beveloid gear with thickened outer convex shape. To internal gear, only gear slotting process can be used, so the formed shape is different with involute beveloid gear. In order to apply the reduction method of return difference characteristics in internal meshing gear reducer, domestic scholar Li Guixian and Li Huamin proposed the oblique slotting machining method, but there is no detail analysis about the difference between two kinds of tooth shape. In this paper, based on previous studies, the difference between the two kinds of beveloid gears are contrasted on forming principle, contact state and section profile contrast, which lay theoretical basis for their promotion and application. 


\section{The Classification of Beveloid Gear}

Involute Beveloid Gear. The geometric feature of involute bavaloid is its modification coefficient changing linearly along the axis. The tooth surface's formation principle can be studied by rack. The tilting angle between the rack indexing plane and the cut gear axis is formed when processing, shown in Fig.1. Keep the relationship of pure rolling sports between rack section plane and gear cylinder plane, then rack's every section is still symmetric trapezium on cross section perpendicular to the axis of the gear. Thereby just the relative gear graduated circle moves "nearer or closer" some distance, resulting in different deflection involute.

Assume that the middle plane in Fig. 1 is zero displacement end face, then the rack section line $t-t$ and the pitch circle with radius of $r_{p}$ will roll, and the contact point $M_{0}$ is exactly coincide with instantaneous centre. Also the gear section shape of every end face has the same base circle, and all the tooth profile's normal line is tangent to the base cylinder. The under end face's tooth profile sectional shape mesh points are $M_{1}, M_{2}$. According to the basic mesh theorem, the common normal line must pass through corresponding points. It is obvious that, points line $P_{1} P_{0} P_{2}$ of the three section plane are parallel with the gear axis. The plane $N_{1} M_{1} M_{2} N_{2}$ composed of normal line, tangency point and meshing point are called meshing plane.

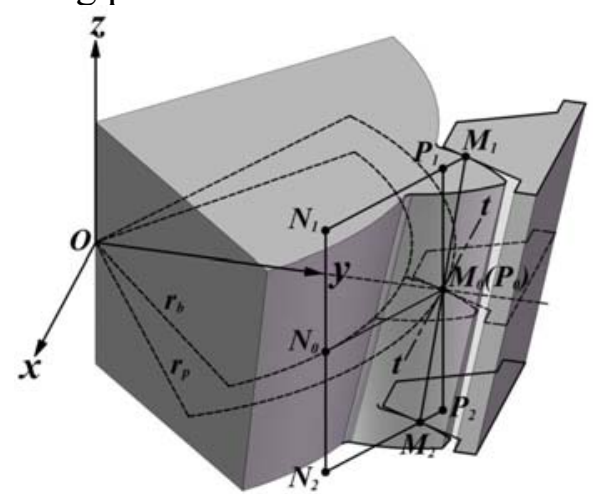

Fig.1 Processing principle of involute beveloid gear

Noninvolute Beveloid Gear. Contrasted with involute beveloid gear machining method, the tooth surface is different when the rack cutting tool is replaced by slotting cutter. From the section plane, perpendicular to the axis of the round billet, the section of rack is still line, while the section of slotting cutter( here as an involute spur gear) is ellipse. The tooth profile cutter shape is not involute line, so the machining gear is different from the involute beveloid gear, which is called noninvolute beveloid gear.

As is shown in Fig.2, the gears are classified to several types by shaft angle between slotting cutter and wheel blank: grade 1 place can be used to process involute straight cylindrical gear; grade 2 place can be used to process noninvolute beveloid gears; 3 and 4 places can be used to process end face gear. There is processing evolution sketch of each gear pair, illustrating that the two beveloid gear's machining principles are defferent.

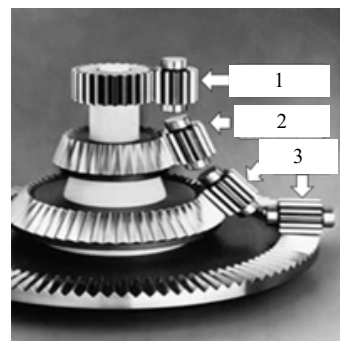

Fig.2 Processing evolution sketch map of each gear pair 


\section{Beveloid Gear Processing Model}

Equations Deduced of Tooth Surface.In Figure 3, the beveloid gear is represented by Roman numerical I, which refers to the involute and non-involute beveloid tooth. The slotting cutter and rack cutter are represented by Roman numerical II, III. For convenient description, the two tools are arranged in the same model.

Coordinate system is established for each member, such as, a global coordinate system $S_{0}$, fixed coordinate system of beveloid gear $S_{1}$, fixed coordinate system of slotting cutter $S_{2}$, fixed coordinate system of rack cutter $S_{3}$, and other auxiliary coordinate systems $S_{P}, S_{2^{\prime}}, S_{3^{\prime}}$, it is visually to be shown that the relative position of the coordinate origin and coordinate axes in Fig.3.

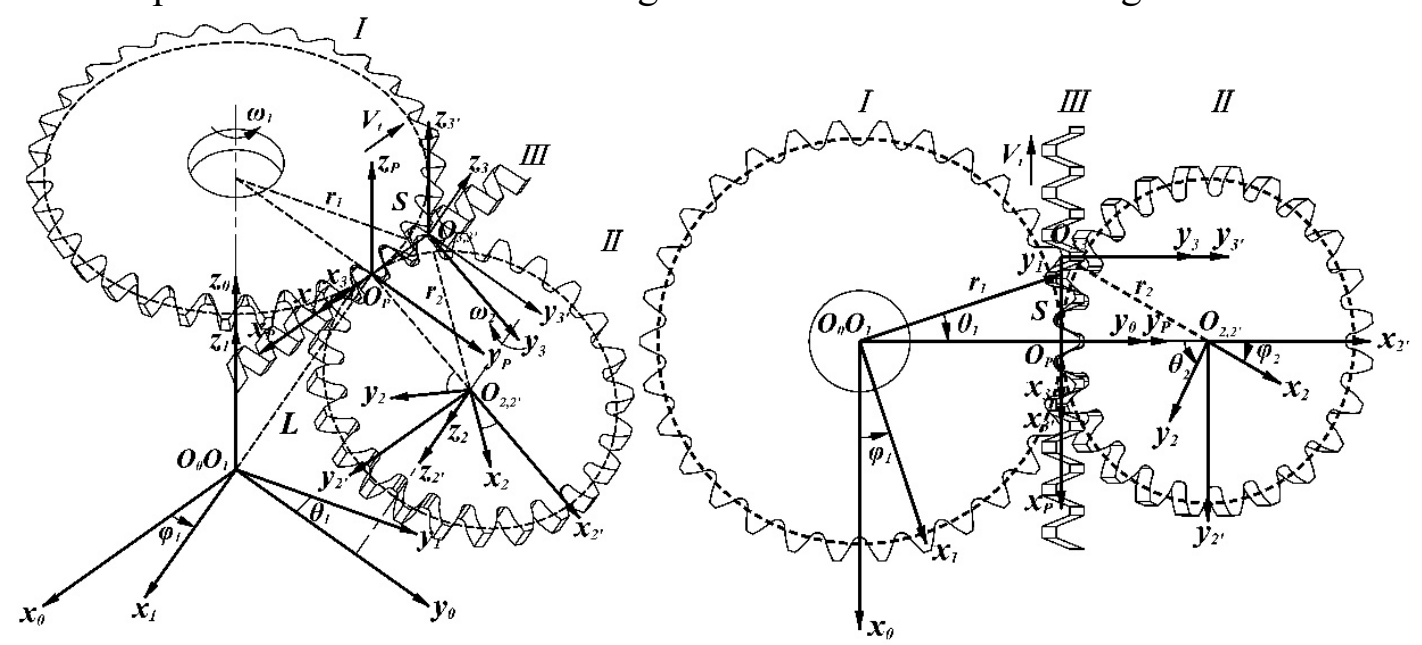

Fig.3 Processing mathematic model of beveloid gear

Tooth surface should be described by two independent variables in the space, assumptions that the slotting cutter tooth surface is represented by $\Sigma_{2}$, and independent variables is represented by $u_{2 a}, u_{2 b}$, the position vector $S_{2}$ in the coordinate system can be written as $\vec{R}_{2}^{2}\left(u_{2 a}, u_{2 b}\right)$, normal vector, erased a variable, can be expressed as $\vec{n}_{2}^{2}\left(u_{2 a}\right)$ or $\vec{n}_{2}^{2}\left(u_{2 b}\right)$.

Similarly, the rack cutter tooth surface is represented by $\Sigma_{3}$, the position vector $S_{3}$ in the coordinate system can be written as $\vec{R}_{3}^{3}\left(u_{3 a}, u_{3 b}\right)$, normal vector, eliminated a variable, can be expressed as $\vec{n}_{3}^{3}\left(u_{3 a}\right)$ or $\vec{n}_{3}^{3}\left(u_{3 b}\right)$.

According to the envelope theory, and combined with conversion between various coordinate matrix, the paper derives the curved surfaces of slotting cutter formed in the beveloid tooth surface fixed coordinate system $S_{1}\left(O_{1}-x_{1}, y_{1}, z_{1}\right)$, which is written as

$$
\vec{R}_{1}^{1}\left(u_{2 a}, u_{2 b}, \varphi_{1}, \varphi_{2}\right)=M s_{1} s_{2}\left(\varphi_{1}, \varphi_{2}\right) \times \vec{R}_{2}^{2}\left(u_{2 a}, u_{2 b}\right)
$$

What is different from slotting cutter for fixed axis rotation is that slotting cutter translation is along the tangent direction, transformation matrix contains translational distance variable $S$, that is $M s_{1} S_{3}\left(\varphi_{1}, S\right)$, so the surface position vector is written as

$$
\vec{R}_{1}^{1}\left(u_{3 a}, u_{3 b}, \varphi_{1}, S\right)=M s_{1} s_{3}\left(\varphi_{1}, S\right) \times \vec{R}_{3}^{3}\left(u_{3 a}, u_{3 b}\right)
$$

Space gear engagement meets the basic mesh theorem, expressed by the mesh equation, namely dot product operations of the relative velocity vector and tooth surface normal vector

(1) meshing equation between slotting cutter and non-involute beveloid gear can be expressed as

$f_{12}\left(u_{2 a}, u_{2 b}, \varphi_{1}, \varphi_{2}\right)=0$

(2) meshing equation between rack cutter and involute beveloid gear can be expressed as

$f_{13}\left(u_{3 a}, u_{3 b}, \varphi_{1}, S\right)=0$

Generating cutting must ensure the pure rolling motion relations between cutter and gear, which is shown as angle relation of cutter fixed coordinate system and blank fixed coordinate system. Assumptions that pitch circle radius of beveloid gear is $r_{1}$, pitch circle radius of slotting cutter is $r_{2}$, then 
$r_{1} \varphi_{1}=r_{2} \varphi_{2}$

$S=r_{1} \varphi_{1}$

Use the above equations, the paper simplifies the curved surface into the desired tooth surface, combines with the formula (1), (3), (5) and eliminates variables $u_{2 a}, \varphi_{1}$ or $u_{2 b}, \varphi_{1}$, then a non-involute beveloid gear tooth surface equation is shown

$\vec{R}_{1}^{1}\left(u_{2 b}, \varphi_{2}\right)$ or $\vec{R}_{1}^{1}\left(u_{2 a}, \varphi_{2}\right)$

Combining Equation (2), (4), (6), and eliminates variables $u_{3 a}, \varphi_{1}$ or $u_{3 b}, \varphi_{1}$, the paper obtains a involute beveloid gear tooth surface equation

$$
\vec{R}_{1}^{1}\left(u_{3 b}, S\right) \text { or } \vec{R}_{1}^{1}\left(u_{3 a}, S\right)
$$

Numerical Computation and Verification.To compare the appearance characteristics of two kind beveloid tooth profile surface, according to the vector equation, the paper presents the spreadsheet calculations shown in Table 1, then calculates the points of mesh equation by Mathematica software, non- involute beveloid tooth surface is represented by red dots (left of Fig. 4) and the involute beveloid tooth surface is represented by gray dots (right of Fig. 4).

Table 1 Basic parameters of beveloid gear

\begin{tabular}{lcc}
\hline \multicolumn{1}{c}{ name } & symbol & value \\
\hline modulus $(\mathrm{mm})$ & $m$ & 4 \\
tooth $(\mathrm{mm})$ & $B$ & 15 \\
pressure $\left({ }^{\circ}\right)$ & $\alpha$ & 20 \\
cone $\left(^{\circ}\right)$ & $\delta$ & 10 \\
addendum & $h_{a}^{*}$ & 0.25 \\
slotting & $z_{2}$ & 18 \\
beveloid & $z_{1}$ & 30 \\
\hline
\end{tabular}

The two kinds of beveloid gears are so similar in profile shown in Fig.4, and tooth appearance are shown a cone, the big end of the addendum is more pointed and teeth thick, however, the small end of the addendum is wider and teeth thinner, which is due to the tilting processing, if the inclination angle is increased, this feature will be more obvious.

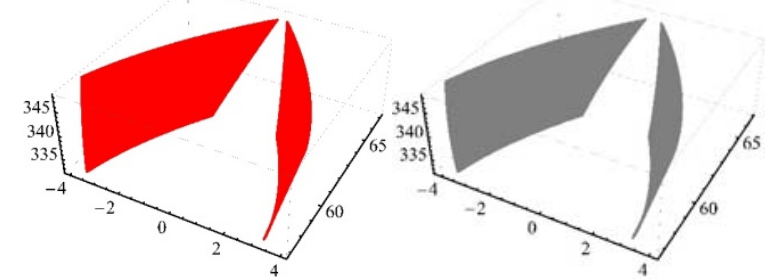

Fig.4 Numerical calculation point set of beveloid gear profile

\section{Tooth Comparison}

For more accurate comparison of two tooth surface, the paper gets teeth truncate with two typical planes and beveloid gear intersects, calculates the difference of the tooth profile corresponding points, in the axial cross-section shown in Figure 5, the two sections are as follows: the one is transverse plane, which is perpendicular to the axis of the wheel blanks, represented by $t-t$, the other is normal plane, which is perpendicular to the axis of the cutters, represented by $n-n$.

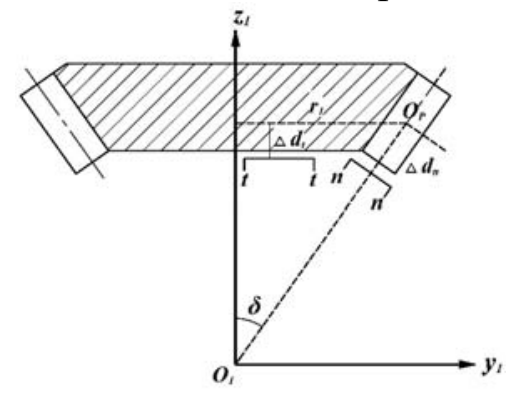

Fig. 5 Normal plane and transverse plane of beveloid gear 
Comparison Method of Transverse Plane Tooth.According to involute beveloid gear properties, the outline of the beveloid gear's transverse plane is involute (nonstandard involute), it is easy to get the base circle, pitch circle, the normal tooth profile and other basic parameters, a point in outline of the beveloid gear is a reference to calculate the cross-section distance between the normal and non-involute tooth, which is standard values of beveloid gear's transverse plane difference.

Assumptions that the distance $\Delta d_{t}$ between transverse plane and transverse plane cross $O_{P}$, the cross-sectional position is expressed as

$z_{1}=r_{1} \cot \delta+\Delta d_{t}$

Simultaneous beveloid gear tooth surface equation (7), (8) to eliminate variables and to obtain the coordinates of the transverse plane of the tooth truncate expression

$$
\begin{aligned}
& \vec{R}_{1}^{1}\left(u_{2 a}\right)=\left[x_{1}\left(u_{2 a}\right), y_{1}\left(u_{2 a}\right)\right] \\
& \vec{R}_{1}^{1}\left(u_{3 a}\right)=\left[x_{1}\left(u_{3 a}\right), y_{1}\left(u_{3 a}\right)\right]
\end{aligned}
$$

Select a point $M_{2}$ in the line involute teeth truncate, by solving the curvature at this point of the curve, the normal equation is expressed as

$$
y_{1}-y_{1}\left(u_{3 a}\right)=-\frac{\partial x_{1}\left(u_{3 a}\right) / \partial u_{3 a}}{\partial y_{1}\left(u_{3 a}\right) / \partial u_{3 a}}\left[x_{1}-x_{1}\left(u_{3 a}\right)\right]
$$

Assumptions that cross-point between the normal and non-involute tooth is $M_{3}$, then the distance between two points can be expressed as

$$
\Delta L=\sqrt{\left[x_{1}\left(u_{3 a}\right)-x_{1}\left(u_{2 a}\right)\right]^{2}+\left[y_{1}\left(u_{3 a}\right)-y_{1}\left(u_{2 a}\right)\right]^{2}}
$$

Comparison Method of Normal Plane Tooth.Although both beveloid gears are not involute in the normal plane, but we can still take advantage of the tooth profile normal to obtain the corresponding point distance, so the normal vector with the unit vector $\vec{i}_{1}, \vec{j}_{1}, \vec{k}_{1}$ in normal section, is represented as

$$
\vec{n}=0 \vec{i}_{1}+\sin \delta \vec{j}_{1}+\cos \delta \vec{k}_{1}
$$

Assumptions that the distance $\Delta d_{n}$ between transverse plane and transverse plane cross $O_{P}$, then in the direction of $O_{1} O_{P}$ to look for the known point coordinates

$$
\left\{0,\left(r_{1} / \sin \delta+\Delta d_{n}\right) \sin \delta,\left(r_{1} / \sin \delta+\Delta d_{n}\right) \cos \delta\right\}
$$

Further results of any normal plane equation are concluded

$$
y_{1} \sin \delta+z_{1} \cos \delta-\frac{r_{1}}{\sin \delta}-\Delta d_{n}=0
$$

The algorithm in section 3.1 is used to solve the intersection point of normal of a transverse plane point in involute beveloid gear and another transverse plane, then get the tooth shape difference.

Difference Curves. The transverse plane and normal plane through the specific node $O_{P}$, since the difference calculation is based on involute beveloid gear transverse plane, the tooth difference should change with the parametric $u_{3 a}$ of rack cutter, and its value range is $\left[0,2 h_{a}^{*} m / \cos \alpha\right]$, showing a gradual change in the addendum from the tool to the root of the tooth and, accordingly, tooth profile of involute beveloid gear should gradually changes from the tooth root to the tooth tip.

Figure 6 and figure 7 show the difference curve of transverse plane tooth varied with variable $u_{3 a}$, the two curves are parabolic shape as a whole, there are the smallest tooth shape difference in the middle of tooth, and the greater difference in the closer to the top of the tooth and the tooth root, but the magnitude of difference is in all below $10^{-4}$, which proves that two kinds of beveloid gears can be replaced each other under certain conditions. 


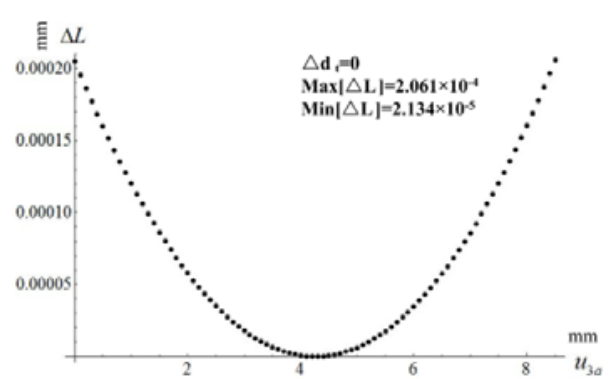

Fig.6 Change Curve of transverse profile of beveloid with variable $u_{3 a}$

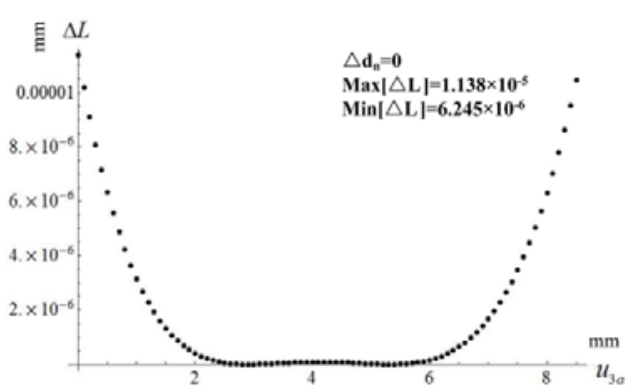

Fig. 7 Change Curve of normal profile of beveloid with variable $u_{3 a}$

\section{Tooth Contact Analysis}

In the process of forming a beveloid gear by generating method, meshing points of the two tooth surface must conform to the principles of meshing and stay in the state of contact line at any instantaneous moment. The instantaneous contact line must be both on the cutter tooth and the beveloid tooth at the same time, and performs as a curve in space.

The instantaneous contact line, as occurrence line, can be solved by the method of simultaneous equations. To solve the simultaneous equation of instantaneous contact line and the cutter tooth, the value of contact line of cutter tooth is derived; and to solve the simultaneous equation of instantaneous contact line and beveloid tooth, the result of contact line of beveloid tooth is also derived.

However, when the processed beveloid gear transmits with cylindrical gears with different number of teeth, the contact method of the two tooth surface changes into point. This kind of situation is most used in practice. Therefore, this section will make detail comparison of the two beveloid gears through the shape of contact line and the formation of point contact.

The Shape Of Contact Line. Non-involute beveloid gear tooth instantaneous contact line. In the representation equation (7) of beveloid tooth, the equation of the position vector of curve surface contains two independent variables. If the angle of pinion cutter $\varphi_{2}$ is a constant, then one of the instantaneous contact line of non- involute beveloid tooth is determined in this meshing state, and is expressed as follow:

$$
\vec{R}_{1}^{1}\left(u_{2 b}\right) \text { or } \vec{R}_{1}^{1}\left(u_{2 a}\right)
$$

According to the parameters in Table 1, when the angle equals to zero, by numerical calculation, the instantaneous contact lines on the left and right sides of the gear teeth are obtained as two blue space curves(Fig. 8 left side view), which are attached to the tooth surface of beveloid gear, changing the value of the rotation angle continuously to get a series of contact lines(Fig. 8 right side view), and forming the tooth profile curve which further proves that the instantaneous contact line is the tooth surface occurrence line.

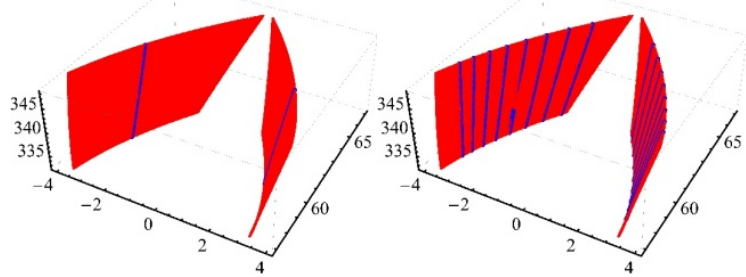

Fig. 8 Instantaneous contact line on non-involute beveloid gear tooth surface

Involute bevoloid gear tooth instantaneous contact line. In like manner, if the shift variable $S$ of rack cutter in equation(8) is a constant, the value of instantaneous contact line on involute beveloid tooth controlled by one-parameter is expressed as:

$$
\vec{R}_{1}^{1}\left(u_{3 b}\right) \text { or } \vec{R}_{1}^{1}\left(u_{3 a}\right)
$$


If the shift variable is zero, to change its value continuously, tooth surface instantaneous contact line represented in Figure 9 is obtained. Compared with Figure 8, tilting attitude of the two beveloid gears are totally different, so as to add to the perspective that two different types of beveloid gears are formed due to the differences in processing methods.

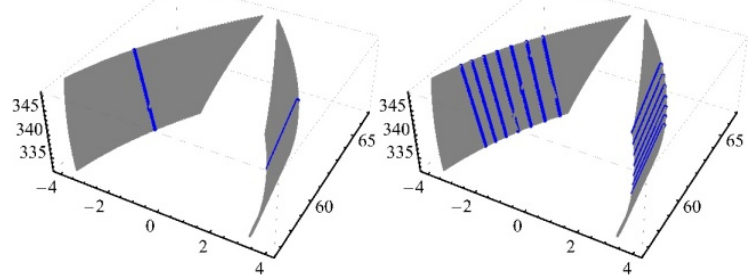

Fig.9 Instantaneous contact line on involute beveloid gear tooth surface

Principle Of Point Contact Formation.If machining cutter is substituted for involute spur gear with equal modulus and different teeth, is meshed with beveloid gear, then a kind of concurrent axes gear transmission type of point contact is derived.

When cutter transmits with spur gear, the instantaneous contact line of the cutter tooth surface is a straight line parallel to the tooth top(Fig.10 as the dotted line shows); when cutter transmits with beveloid gear, the instantaneous contact line of the cutter tooth surface is the titling space curve(Fig.10 as the solid line shows). Two contact lines are mapped to the cutter tooth surface, intersect at one point, then change into the state of point contact.

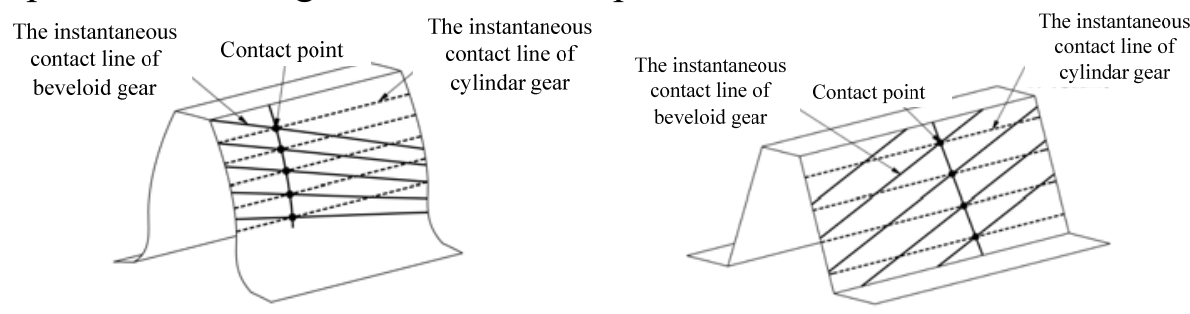

Fig.10 Instantaneous contact point on cutter tooth surface

Continuous Contact Track. In order to obtain the flow path of the contact point on the beveloid gear tooth, the following ideas are adopted: find the mesh equation of cylinder gear and cutter firstly, solve the equation to get the value of instantaneous contact line of cutter tooth; secondly, to solve the instantaneous contact line of cutter making use of the mesh equation of beveloid gear and cutter; then, make the two equations above into simultaneous equation to get the instantaneous contact line of cutter tooth by solving the equation. By means of coordinate transformation and continuous change of the rotation angle, the flow path of beveloid tooth is got.

Take non-involute beveloid tooth for example, combined with vector formula in Section 2, the flow path of the contact point on the tooth surface is calculated. As is shown in Fig.11, contact track is restricted to the middle of the tooth width, edge contact is avoided, and the contact strength is better, it is the desired position in theory. So this type of transmission is applied in the ship gear case and other heavy load occasions.

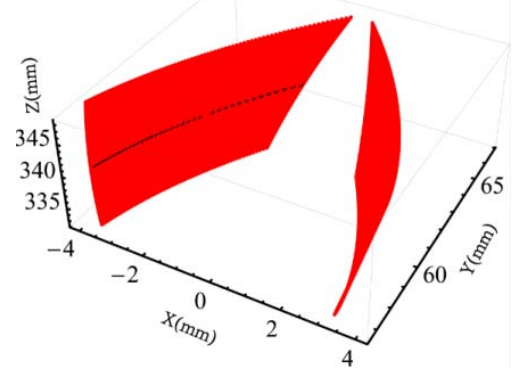

Fig.11 Continuous contact track of beveloid tooth surface 


\section{Conclusion}

Beveloid gear is a kind of equal modulus, equal height of depth gear to proceed the generating process through adjusting the angle of inclination between the cutters and the wheel blank axis. On the end section, the truncate of rack cutter is an isosceles trapezoid, and the truncate of pinion cutter is non-involute, according to envelope principle, two different types of develoid gears are formed.

By setting up the mathematical model of beveloid gear machining, position vector equation of tooth surface is derived. The appearances of gear teeth derived by calculation are with very similar characteristics, which are in taper shape, big tips are sharp and small tips are thick.

Corresponding truncate is obtained by intersecting the end section and normal section with the beveloid gear. Difference of normal direction is calculated by making use of one point of involute profile as datum. A curve changing with parameters is got, and the result shows that difference at the middle of the tooth's height is minimum, and the overall value is up to the level that can be ignored, and it is proved that the two beveloid gears can be approximate substitution to each other in a certain degree.

Different processing principle will inevitably lead to the difference between tooth surface of instantaneous contact line, and the inclined posture of contact line is especially different. This phenomenon is especially obvious on the cutter surface. And when involute spur gears with different number of teeth transmit with cutter surface, line contact changes into point contact, the contact track remains in the middle part of the gear width, and it's a kind of ideal transmission type.

\section{References}

[1] Li H M, et al. The Geometric Principle and Calculation of Involute Gear [M]. Beijing: Machinery Industry Press, 1985

[2] Zhu X L. Handebook of Gear Design [M]. Beijing: Chemical Industry Press, 2010

[3] Li G X, Wu J F, Li H M. The Design and Calculation of Internal Involute Bevoloid Gears with Parallel Axes [J]. China Mechanical Engineering, 2000, 11(8):886-889

[4] He J L, Wu X T. On the Hobbing Principle of Conical Involute Gears [J]. Mechanical Science and Technology, 2003, 22(5):751-753

[5] Mitome K. Design of Miter Conical Involute Gears Based on Tooth Bearing [J]. JSME International Journal Series C-Mechanical Systems Machine Elements and Manufacturing, 1995, 38(2): $307-311$

[6] Mitome K. Concave Conical Gear [J]. Transactions of the Japan Society of Mechanical Engineers. 1999, Vol. 65(632): 1629-1634

[7] Brauer J. Analytical Geometry of Straight Conical Involute Gears [J]. Mechanism and Machine Theory, 2002, 37:127-141

[8] He J L, Wu X T. Study on Gearing Principle of Crossed-axes Conical Involute Gears [J]. Journal of Mechanical Engineering, 2004, 40(4): 81-84

[9] He J L, Wu X T. Study on Geometrical Design of Conical Involute Gear Pair with Nonintersecting-Nonparallel-Axes [J]. Journal of Xian Jiaotong University, 2003, 37(5):471-474 